\title{
The Structural design of banknotes plastic packing machine
}

\author{
HanMing-bo ${ }^{1, a^{*}}$, Sun Li-fei ${ }^{2, b}$ \\ ${ }^{1}$ School of Applied Technology, University of Science and Technology Liaoning, Anshan, 114051, \\ China \\ ${ }^{2}$ School of Software Technology, University of Science and Technology Liaoning, Anshan, 114051, \\ China \\ a41397803@qq.com, b177282841@qq.com
}

Keywords: Banknotes; Plastic film; Plastic packing machine; Structural design; Advantages Abstract. In this paper, the design significance of plastic packing machine, the difference between the new and previous plastic packing machine and the advantages of the plastic packing machine is elaborated. The plastic packing machine is composed of the banknotes push and the bill alignment part, plastic film packaging, thermoplastic molding part and control part. The structure and working principle of each component are described respectively.

\section{Introduction of Foreword}

With the rapid development of China's economy, financial machinery are increasingly high required. Banknotes plastic packaging machine is an important factor to improve the work efficiency of bank and ensure financial action, safety, accuracy and reliability. But now a lot of financial institutions to use double cross binding to save and circulate bills, it must be tied tightly bound to prison, to prevent pumping. But tied too tight, money is easy to cause damage and when the tied must be completed we a paste or glue a banding on bills. Demolition, sometimes damage the top of bills. The bundle of bills in the process of storage and transportation easy to damp, mildew, metamorphism. All these factors have greatly reduced the service life of the money. The general banking financial institutions may not buy large plastic equipment. Small foreign equipment but expensive So we must design a banknotes plastic packaging machine meets the requirements of miniaturization strapping and packing integration. ${ }^{[1]}$

\section{The structure and working principle of banknotes plastic packing machine}

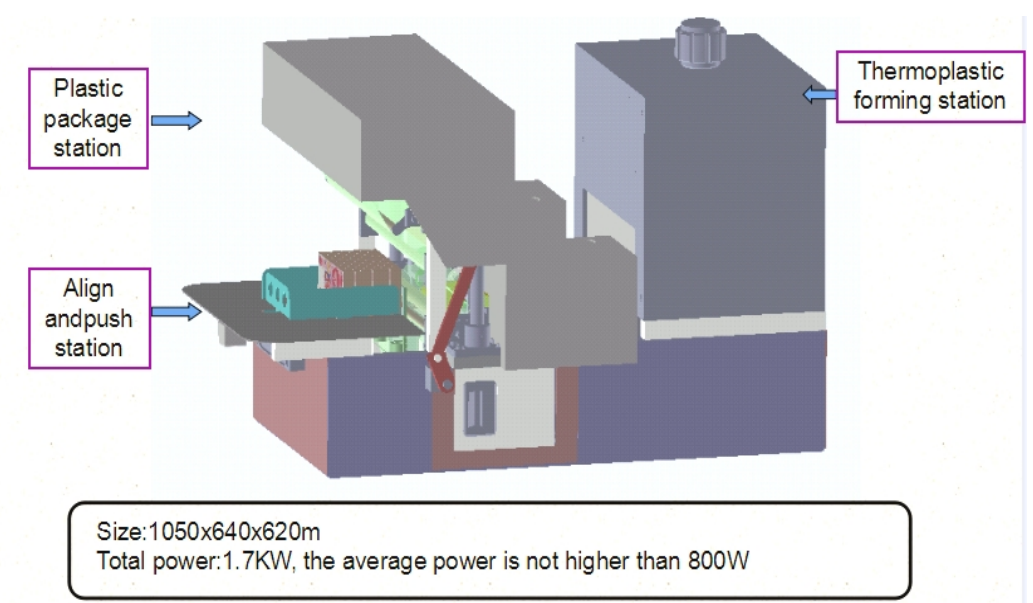

Figure 1 plastic packaging machine specifications and components

Alignment and pushing station. The device is divided into upper and lower two parts by the cover plate, which is composed of a baffle plate, a push plate and two side plates, put ten bundles of money in it by people. Because of the ten bundles of hundred dollar bills free to put up about 160mm, paper 
money long $177 \mathrm{~mm}$, so this space is set to $200 \mathrm{mmX} 190 \mathrm{~mm}$. The following is composed of a screw and a nut sliding seat. The strip electromagnet is not energized ,the baffle under the action of spring force is in the top of cover plate.

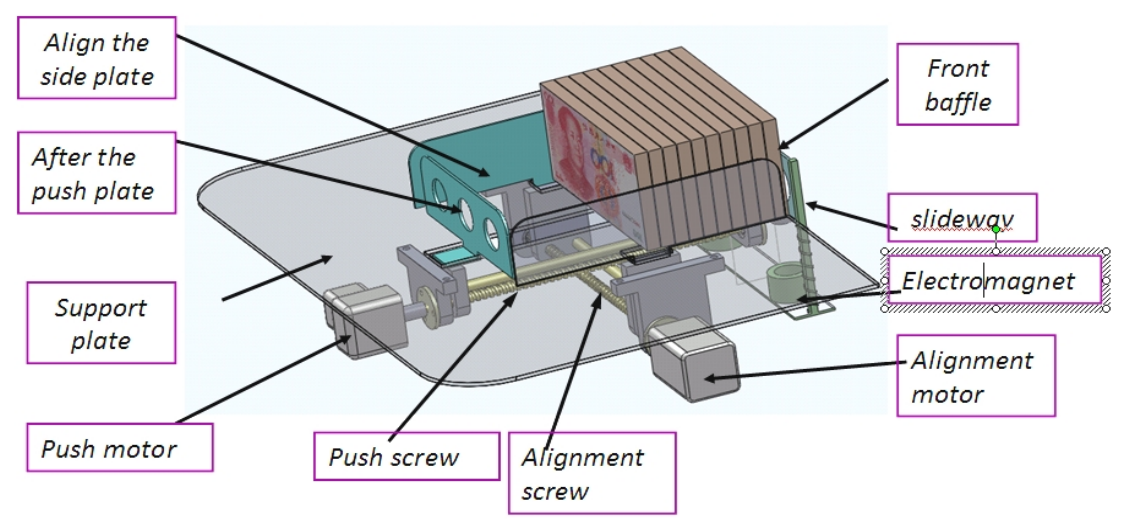

Figure 2 alignment and pushing station

When ten bundles of money are placed in the apron, pressing the start switch button, the motor through the coupling to drive the screw rod to rotate; by nut slide block the pushing plate drives the banknotes in both side plates to form the slide inward movement to the baffle plate and pressing effect. Then pushing board suspended, on opposite sides two separately left and right screw nut slide block on the horizontal bar drives the bills towards the center. Both sides plate make the bundle of money alignment and then outward separate a certain gap to form a slide way. When the Electromagnets electrified, the baffle plate under the action of electromagnetic force is at the lower end, The pushing plate to push the bills on tight plastic film and to drive the plastic film forward movement to form a plastic bag containing money. Push back The pushing plate after package, the packing station made thermoplastic money tied. Electromagnet is power cut, the baffle under the action of Spring force is at the upper end. When placed in the other face of the banknotes, the space is consist of by the baffle plate, push plate and the two side plate can be adjusted to.

Plastic film packing station. Plastic film packing station main including the up film conveying mechanism and the down conveying mechanism of membrane, membrane cutting knife mechanism, a belt conveyor, chain traction mechanism and waste winding mechanism, etc. ${ }^{[2,3]}$

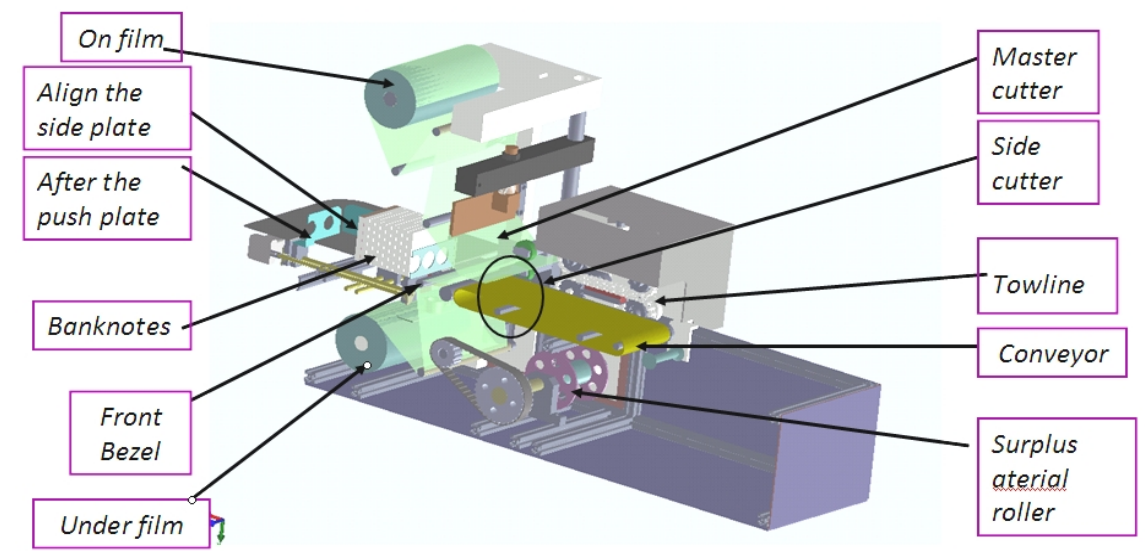

Figure 3 plastic film packing station

The up film and the lower film respectively from the on film conveying mechanism and the lower film conveying mechanism is dragged to mold package station entrance, by the main cutting knife is heated and fused into one, alignment pushing and sending station push bills with packaging film forward to formation of a plastic bag, and to press the bills. In the process of advancing, both sides of the membrane is sealed off by side cutter. Scrap by towline traction is dragged to the remaining 
material stick for recycling. Photoelectric switches to detect to notes in place going forward and signaling, alignment pushing and sending station retracement and the main cutting knife run down to cut the upper and lower film off and to fusion it. One side of the bills is packed; on the other side, the film is fused together. when the main cutting knife run upward, alignment pushing and sending station push next batch of bills coming, package of the next cycle will be started.

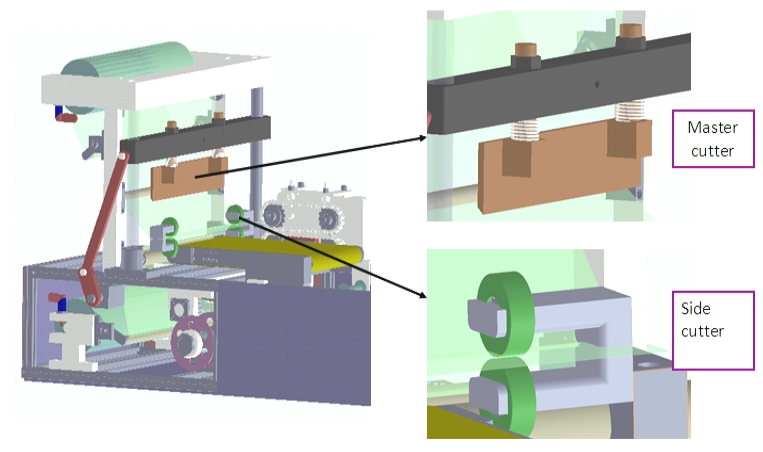

Figure 4 main cutter mechanism

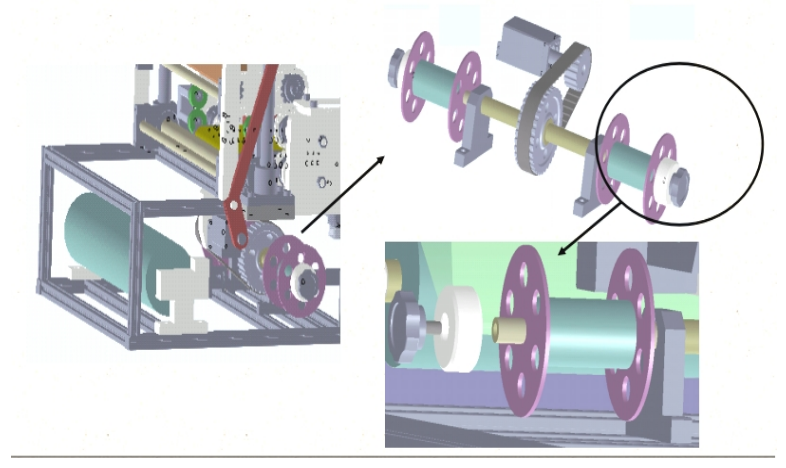

Figure 6 scrap material Collection mechanism

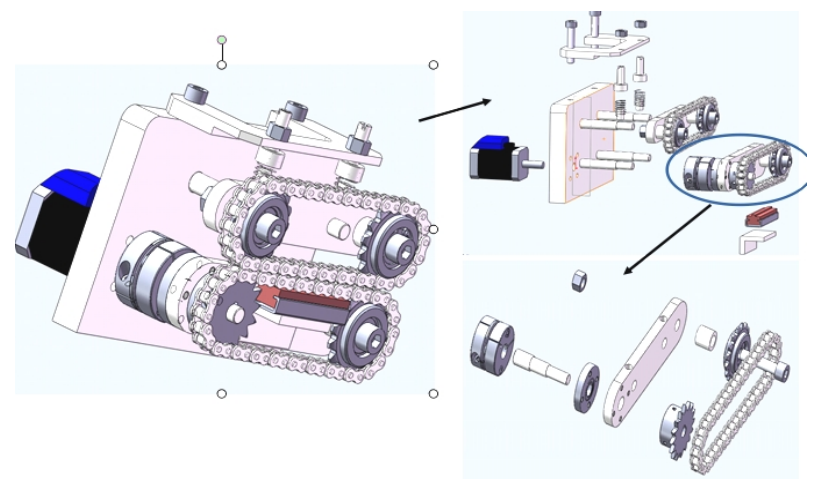

Figure5 drag chain mechanism

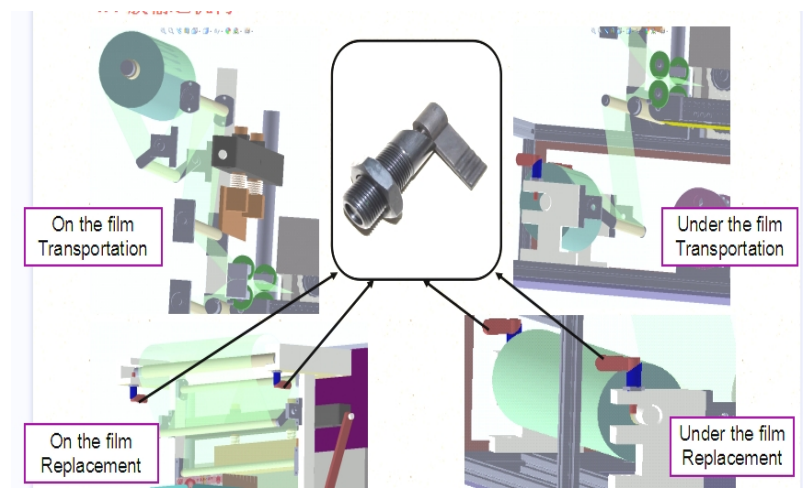

Figure 7 film transport mechanism

Thermoplastic forming station. The thermal plastic forming part use the shrinkage force of the packaging film is used to heat which can be used to wrap a group of items to be packed, play a very good binding effect. After screening we used POF heat shrink packing film. This film has good transparency, good gloss, good flexibility, easy to use, high shrinkage, high shrinkage rate of $25 \%$, good welding sealing performance, high strength, suitable for manual, semi automatic and high speed automatic packaging, good cold resistance, environmental protection, non-toxic, low cost, etc. [4]

The main equipment is hot air circulation oven. It mainly consist of the mechanical part and electric control part. Mechanical part mainly consists of an oven body, an infrared heating tube, circulating fan, air deflector, fan motor, fan, diversion grid etc. components.

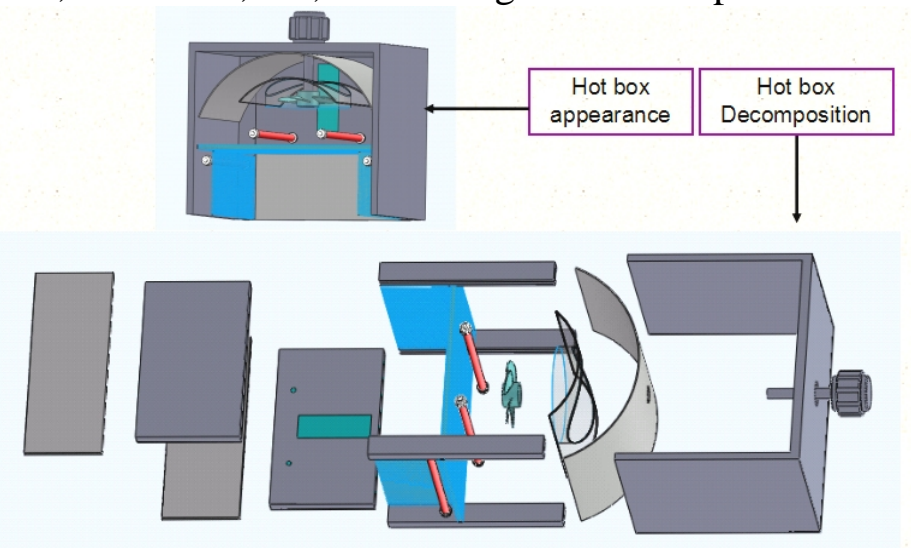

Figure 8 hot plastic forming station 
The oven adopts 4 infrared heating tubes (about 200W per power), arranged in the middle of the oven. Air circulation system of hot air circulation oven use circulating fan air supply mode, intermediate ceiling wind (wind by upward), the wind guide plate shunt the hot wind blowing from the both sides of the box body and from top to bottom blowing. The diversion grid diversion, the thermal airflow uniform sounded conveyor belt on the package of POF film, circulating air uniform. Air supply of circulating air motor drives the wind wheel through a heater heating circulation, the hot air is blown out. Hot air temperature can automatically is adjusted according to the change of environment temperature and the speed of the conveyor belt.

\section{Summary}

The machine of the independent development of optoelectronic integrated equipments can achieve 10 notes of semi-automatic and fully automatic plastic packing. This product is specially for banknotes plastic package, which has the advantages of simple structure, high reliability. Because of its relatively low total power, the energy saving effect is good. The whole machine is not used for pneumatic components. The process of automatic control is realized by mechanical structure and electrical control. It can reduce the noise and reduce the cost. Pressing the execute button, the machine can automatically plastic sealing molding for notes, without the need for pre tie。Also the machine through the simple adjustment part alignment and push feed mechanism after can convergence with a single bundle of banknotes automation line, to the flat notes flip With compared to the previous plastic packing machine, the machine adopts double film structure, greatly simplifying the film feeding mechanism and reduce the area and bundle size of the film, the plastic film easy to operate and control, the plastic appearance is beautiful and neat. And this machine has the advantages of small volume, production rate high, competitive, so it is mainly used to the commercial bank cash processing center and large and medium -sized business outlets and other large financial institutions

\section{References}

[1]. Xu Lincheng Zhao Zhihua Wang Ye Etc. Packaging machinery principle and design [M] Shanghai: ShanghaiScience and Technology Press. 1988 5 8.

[2]Zhou Xiangxing: let Xiancheng. Plastic packaging materials and molding technology [M] Beijing: Chemical Industry Press.2004.10 22.

[3]Peng Guoxun. On the packaging machinery[M]. Beijing: Mechanical Industry Press 1985. 20 25

[4] Huang Qiyou. Plastic packaging film ---production· Performance. Application [M]. Beijing:

Mechanical Industry Press 2003. 4 5. 